\title{
ANALISIS KELAYAKAN FINANSIAL USAHATANI \\ KOMODITAS DUKU (Lansium domestikum) \\ PADA KELOMPOK TANI HARAPAN MAKMUR \\ (Studi Kasus di Dusun Cililitan Desa Karanganyar Kecamatan Cijeungjing Kabupaten Ciamis)
}

\author{
ARI NURHIDAYAT ${ }^{1 *}$, DINI ROCHDIANI ${ }^{2}$, SUDRAJAT $^{1}$ \\ ${ }^{1}$ Fakultas Pertanian Universitas Galuh \\ ${ }^{2}$ Fakultas Pertanian Universitas Padjadjaran \\ *E-mail : arinurhidayat69@gmail.com
}

\begin{abstract}
ABSTRAK
Tujuan penelitian ini adalah mengetahui : (1) Kelayakan finansial usahatani duku yang diusahakan para petani pada Kelompok Tani Harapan Makmur Dusun Cililitan Desa Karanganyar Kecamatan Cijeungjing Kabupaten Ciamis, (2) Jangka waktu yang diperlukan untuk mengembalikan seluruh modal yang diinvestasikan pada usahatani duku yang diusahakan para petani pada Kelompok Tani Harapan Makmur Dusun Cililitan Desa Karanganyar Kecamatan Cijeungjing Kabupaten Ciamis. Metode penelitian yang digunakan dalam penelitian ini adalah metode studi kasus. Penarikan responden dilakukan secara sampling jenuh, pada semua petani yang mengusahakan duku pada Kelompok Tani Harapan Makmur Dusun Cililitan Desa Karanganyar Kecamatan Cijeungjing Kabupaten Ciamis yaitu sebanyak 5 orang. Analisis yang digunakan yaitu analisis kelayakan finansial dengan menggunakan rumus NPV, IRR, Net B/C dan Payback Periods. Hasil penelitian menunjukkan : 1) Besarnya rata-rata biaya investasi usahatani duku per hektar pada Kelompok Tani Harapan Makmur di Dusun Cililitan Desa Karanganyar Kecamatan Cijeungjing sebesar Rp. 74.707.900,00. Rata-rata biaya operasional usahatani duku per hektar untuk tahun ke-1 sampai tahun ke-9 adalah Rp. 1.572.981,20 sedangkan rata-rata biaya operasional usahatani duku per hektar untuk tahun ke-10 sampai tahun ke-30 adalah Rp. 7.066.812,00. Rata-rata penerimaan usahatani duku per hektar pada Kelompok Tani Harapan Makmur di Dusun Cililitan Desa Karanganyar Kecamatan Cijeungjing sebesar Rp. 1.023.753.600,00. Nilai rata-rata $N P V$ per hektar sebesar Rp. 35.758.175,22. Berarti responden memperoleh keuntungan pada tingkat bunga 7 persen sebesar Rp. 35.758.175,22. Nilai ratarata $\mathrm{Net} B / C$ sebesar 1,41 ini berarti setiap 1,00 modal yang ditanam pada usahatani duku akan memperoleh manfaaat sebesar 1,41 . Nilai rata-rata $I R R$ yang diperoleh sebesar 8,83 persen, berarti tingkat bunga bank maksimum yang mampu dibayar oleh responden sebesar 8,83 persen per tahun atau lebih besar dari tingkat bunga 7 persen. Dilihat dari $N P V$, Net B/C dan IRR maka usahatani duku pada Kelompok Tani Harapan Makmur di Dusun Cililitan Desa Karanganyar Kecamatan Cijeungjing layak untuk diusahakan, karena nilai $N P V$ nya lebih dari $0, N e t$ B/C lebih dari 1 , dan IRR nya lebih besar dari tingkat bunga bank yang berlaku. 2) Rata-rata jangka waktu pengembalian modal yang diinvestasikan dalam usahatani duku di Kelompok Tani Harapan Makmur Dusun Cililitan Desa Karanganyar yaitu 20 tahun 6 bulan 20 hari.
\end{abstract}

Kata Kunci : Kelayakan Finansial, $N P V$, Net B/C, IRR, Buah Duku.

\section{ABSTRACT}

The purpose of this research is to find out: (1) The financial feasibility of the duku farming undertaken by all farmers in the farmer group Hope Makmur Dusun Cililitan Village Karanganyar Ciamis District, (2) the timeframe that necessary to restore all the capital invested in the farming duku that is cultivated by all farmers in the farmer group Harapan Makmur Dusun Cililitan Village Karanganyar District Cijeungjing Ciamis. The research method used in this research is the case study method. The respondent's withdrawal in this study is sampling saturated, all farmers who are working on the farmer group Harapan Makmur Dusun Cililitan Village Karanganyar District Cijeungjing Ciamis as many as 5 people used as a sample. The analysis used in this research is a financial feasibility 
analysis that is using the formula NPV, IRR, Net B/C and Payback Periods.The results showed: 1) the average amount of investment costs of duku per hectare in the Farmers Hope prosperous group in Dusun Cililitan Karanganyar District Cijeungjing amounting to Rp. 74.707.900,00. The average operating cost of the farming duku per hectare for the 1st year to the 9th year is Rp. 1.572.981,20 while the average operating cost of the farming duku per hectare for the 10th year to the 30th year is Rp. 7.066.812,00. The average acceptance of the farming duku per hectare on the farmer Hope Prosperous group in Dusun Cililitan Karanganyar Village District Cijeungjing amounting to Rp. 1.023.753.600,00. The average value of NPV per hectare is $R p .35 .758 .175,22$. Means the respondent gains at 7 percent interest rate of $R p . R p .35 .758 .175,22$. The average value of the Net B/C of 1.41 is that every 1.00 of the capital planted in farming Duku will get the benefit of 1.41. The average value of IRR earned is 8.83 percent, meaning the maximum bank interest rate payable by respondents amounted to 8.83 percent per year or greater than 7 percent interest rate. Judging from NPV, Net B/C and IRR, the farm in the farmer Hope Prosperous group in Dusun Cililitan Karanganyar District Cijeungjing deserves to be cultivated, because the value of NPV is more than $0, N e t$ B/C more than 1 , and its IRR greater than the interest rate The applicable bank. 2) The average time period of the return of the invested capital in the activities of the business of Duku in the respondents farmer group Harapan Makmur Dusun Cililitan Village of Karanganyar is 20 years 6 months 20 days.

Keywords: financial feasibility, NPV, Net B/C, IRR fruit Duku.

\section{PENDAHULUAN}

Umumnya setiap pembangunan yang semakin meningkat dan berkembang membawa konsekuensi pada peningkatan kebutuhan akan sumber daya alam seperti hutan, tanah dan air. Untuk mencapai kondisi yang diharapkan, penggunaan dan pemanfaatan sumber daya alam bagi kepentingan pembangunan harus dilakukan secara bijaksana ditunjang dengan perencanaan yang menyeluruh, terarah dan berkesinambungan sehingga berbagai kepentingan dapat berinteraksi secara harmonis dan serasi (Atmaja dan Hartoyo, 2005).

Seiring dengan ketatnya persaingan antar negara, sektor pertanian dituntut agar dapat memacu pusat-pusat pertumbuhan baru yang dapat memberikan pengaruh signifikan terhadap pembangunan ekonomi nasional (Azhari, 2004). Salah satu pusat pertumbuhan baru yang sangat potensial dikembangkan pada masa kini dan masa depan adalah subsektor hortikultura. Subsektor ini memegang peranan penting dalam pertanian Indonesia secara umum.

Komoditas hortikultura yang dapat digunakan dan dikembangkan untuk orientasi tersebut adalah buah-buahan. Hal tersebut disebabkan komoditas ini memiliki keunggulan komparatif dan kompetitif baik di pasar dalam negeri maupun internasional (Azhari, 2004).

\section{Duku (Lansium domesticum)} merupakan salah satu jenis buah-buahan yang sudah ada sejak lama dan dikenal di Indonesia. Komoditas ini diperkirakan sebagai tanaman asli Asia Tenggara. Duku memiliki daging buah yang berwarna putih bening, jernih, dan rasanya manis. Oleh 
karena itu, buah duku sangat digemari oleh masyarakat. Namun sayangnya, buah duku tidak dapat dikonsumsi tiap saat, karena tanaman duku termasuk jenis tanaman yang berbuah satu kali saja untuk setiap tahunnya (Lutony, 2005).

Kecamatan Cijeungjing memiliki tanaman duku dengan jumlah pohon yang dipanen 16.000 pohon, produksi 8.000 kwintal, dan produktivitasnya mencapai 0,50 kwintal per pohon. Hal tersebut menunjukkan bahwa produksi tanaman duku di Kecamatan Cijeungjing paling tinggi dibandingkan dengan kecamatan lainnya di Kabupaten Ciamis.

Penanaman duku di Kecamatan Cijeungjing tersebar di 11 desa. Desa Karanganyar memiliki luas areal panen duku paling Luas di Kecamatan Cijeungjing yaitu 68,60 hektar dengan produksi 447,66 ton dan produktivitasnya 6,52 ton per hektar. Dengan tingginya produksi duku di Desa Karanganyar pendapatan petani duku pun cukup tinggi. Peningkatan pendapatan petani duku dapat terjadi apabila diiringi dengan peningkatan teknologi dan mutu walaupun dibutuhkan investasi yang besar. Masalah ini mendorong para pelaku agribisnis harus melakukan studi kelayakan secara finansial agar diketahui apakah investasi yang ditanamkan dapat memberikan keuntungan atau tidak.

Di Desa Karanganyar hampir seluruh penduduknya mempunyai pohon duku. Dari semua petani duku di Desa Karanganyar terdapat lima orang petani yang tergabung pada Kelompok Tani Harapan Makmur di Dusun Cililitan Desa Karanganyar Kecamatan Cijeungjing Kabupaten Ciamis dengan tujuan untuk memperoleh hasil produksi yang baik.

Berdasarkan data yang diperoleh diketahui bahwa semua petani duku yang tergabung pada Kelompok Tani Harapan Makmur belum melakukan analisis finansial mengenai kelayakan dari usahatani duku yang diusahakannya. Oleh sebab itu, penulis tertarik untuk meneliti kelayakan finansial usahatani duku. Analisis kelayakan finansial dipilih karena tanaman duku adalah tanaman hortikultura yang berumur tahunan.

\section{METODE PENELITIAN}

\section{Jenis Penelitian}

Jenis penelitian yang digunakan dalam penelitian ini adalah studi kasus, dengan mengambil kasus pada Kelompok Tani Harapan Makmur di Dusun Cililitan Desa Karanganyar Kecamatan Cijeungjing Kabupaten Ciamis. Menurut Daniel (2002) studi kasus merupakan penelitian pada 
objek yang akan diteliti lebih terarah atau terfokus pada sifat tertentu yang tidak berlaku umum.

\section{Teknik Pengumpulan Data}

Data yang dikumpulkan dan berhubungan dengan penelitian ini adalah :

1. Data primer diperoleh dari petani responden yang dilakukan melalui wawancara langsung dengan menggunakan daftar pertanyaan (kuesioner) yang telah disiapkan.

2. Data sekunder diperoleh melalui studi pustaka dan kunjungan langsung ke lembaga atau instansi yang terkait dengan penelitian ini.

\section{Teknik Penarikan Responden}

Responden dalam penelitian ini diambil menggunakan sampling jenuh. Menurut Sugiyono (2015) sampling jenuh adalah teknik penentuan sampel bila semua anggota populasi digunakan sebagai sampel. Jumlah petani yang mengusahakan duku pada Kelompok Tani Harapan Makmur di Dusun Cililitan Desa Karanganyar Kecamatan Cijeungjing Kabupaten Ciamis sebanyak 5 orang, sehingga jumlah sampel yang dijadikan responden berjumlah 5 orang.

\section{Rancangan Analisis Data}

a. Rancangan Analisis Data

Data yang diperoleh dianalisis dengan menggunakan metode analisis kelayakan usaha. Untuk menganalisis usahatani duku pada Kelompok Tani Harapan Makmur di Dusun Cililitan Desa Karanganyar Kecamatan Cijeungjing Kabupaten Ciamis digunakan rumus sebagai berikut :

\section{1) Net Present Value (NPV)}

Cara menghitung NPV menggunakan rumus sebagai berikut (Husnan dan Muhamad, 2008) :

$$
\begin{aligned}
& N P V=\sum_{{ }^{\prime} t=0}{ }^{t=n} \frac{B t-C t}{(1+i)^{1}} \\
& N P V=\sum(B t-C t) D f \\
& N P V=\sum(\text { Net Benefit }) D f
\end{aligned}
$$

Keterangan :

$\mathrm{Bt}=$ Benefit pada tahun ke $\mathrm{t}$

$\mathrm{Ct}=$ Cost pada tahun ke $\mathrm{t}$

Df $=$ Discount Factor

Kaidah keputusan :

a. Jika $N P V>0$ maka proyek layak diusahakan atau menguntungkan.

b. Jika $N P V<0$ maka proyek tidak layak diusahakan atau rugi.

\section{2) Net Benefit of Cost Ratio ( Net B/C)}

Cara menghitung Net $\mathrm{B} / \mathrm{C}$ menggunakan rumus sebagai berikut (Husnan dan Muhamad, 2008) :

$$
\begin{aligned}
& \text { Net } B / C=\frac{\sum_{t=0}^{t=n} \frac{B t-C t}{(1+i)^{1}}}{\sum_{\substack{t=n \\
t=0}} \frac{B t-C t}{(1+i)^{1}}} \\
& \text { Net } B / C=\frac{\sum(\text { Net Benefit Positif })(D f)}{\sum(\text { Net Benefit Negatif })(D f)} \\
& \text { Net } B / C=\frac{\sum N P V \text { Positif }}{\sum N P V \text { Negatif }}
\end{aligned}
$$


Kaidah keputusan :

a. Jika $N e t B / C>1$ maka proyek layak diusahakan.

b. Jika Net $B / C<1$ maka proyek tidak layak diusahakan.

\section{3) Internal Rate of Return (IRR)}

Untuk mengetahui IRR digunakan rumus sebagai berikut (Husnan dan Muhamad, 2008) :

$$
I R R=\mathrm{i}_{1}+\frac{N P V^{+}}{N P V_{1}^{+} N P V_{2}^{-}}\left(i_{2}-i_{1}\right)
$$

Keterangan :

$\mathrm{i}_{1}=$ Discount Rate pertama dimana diperoleh $N P V$ positif.

$\mathrm{I}_{2}=$ Discount Rate kedua dimana diperoleh $N P V$ negatif.

Kaidah keputusan :

Jika $I R R>$ bunga bank yang berlaku maka proyek menguntungkan.

Jika $I R R<$ bunga bank yang berlaku maka proyek rugi.

\section{4) Payback Periods}

Payback Periods merupakan jangka waktu kembalinya investasi yang telah dikeluarkan, melalui keuntungan yang diperoleh dari suatu proyek yang telah direncanakan, maka menggunakan rumus sebagai berikut :

$$
\mathrm{PBP}=T_{p-1}+\frac{\sum_{i=1}^{n} I_{i}-\sum_{i=1}^{n} B_{i c p}-1}{B p}
$$

Keterangan :

PBP = Payback Periods

$\mathrm{T}_{\mathrm{p}-1}=$ Tahun sebelum terdapat $P B P$
$\mathrm{I}_{\mathrm{i}} \quad=$ Jumlah investasi telah didiskon

$\mathrm{B}_{\text {icp-1 }}=$ Jumlah benefit yang telah

didiskon sebelum $P B P$

$\mathrm{Bp} \quad=$ Jumlah benefit pada $P B P$

\section{HASIL DAN PEMBAHASAN}

\section{Identitas Responden}

Umur responden petani duku yang tergabung dalam Kelompok Tani Harapan Makmur di Dusun Cililitan Desa Karanganyar Kecamatan Cijeungjing Kabupaten Ciamis kebanyakan berada pada usia tidak produktif karena yang berumur di atas 64 tahun sejumlah 3 orang dengan persentase 60,00 persen. Menurut Ritonga (2003) usia produktif adalah penduduk berumur 15 sampai 64 tahun.

\section{Analisis Kelayakan Usahatani Duku}

\section{Biaya Investasi}

Biaya investasi merupakan seluruh biaya yang dikeluarkan sebelum usahatani duku itu berjalan, biaya investasi dalam usahatani duku yang dikeluarkan oleh petani responden terdiri dari pembelian lahan, biaya tenaga kerja, pembelian bibit, pembelian pupuk, dan pembelian peralatan. Total rata-rata biaya investasi usahatani duku per hektar pada Kelompok Tani Harapan Makmur di Dusun Cililitan Desa Karanganyar Kecamatan Cijeungjing sebesar Rp. 74.707.900,00. 


\section{Biaya Operasional}

Penggunaan biaya operasional yaitu untuk pembayaran pajak lahan, pembelian pupuk anorganik dan pupuk kandang, pembelian insektisida, pembelian fungisida, dan biaya tenaga kerja. Rata-rata biaya operasional usahatani duku per hektar untuk tahun ke-1 sampai tahun ke-9 adalah Rp. 1.572.981,20 sedangkan ratarata biaya operasional usahatani duku per hektar untuk tahun ke-10 sampai tahun ke30 adalah Rp. 7.066.812,00.

\section{Penerimaan}

Penerimaan merupakan hasil perkalian antara jumlah produk dengan harga jual produk tersebut. Penerimaan dalam usahatani duku diperoleh dari penjualan buah duku. Rata-rata penerimaan usahatani duku per hektar pada Kelompok Tani Harapan Makmur di Dusun Cililitan Desa Karanganyar Kecamatan Cijeungjing sebesar Rp. 1.023.753.600,00.

\section{Analisis Kelayakan Finansial}

Untuk melihat kelayakan usahatani duku yang diusahakan petani pada Kelompok Tani Harapan Makmur di Dusun Cililitan Desa Karanganyar Kecamatan Cijeungjing menggunakan perhitungan analisis investasi pada tingkat bunga $7 \%$ per tahun, tingkat bunga tersebut merupakan tingkat bunga yang berlaku di tempat penelitian.

\section{a) NPV}

Net Present Value (NPV) atau nilai bersih sekarang merupakan selisih antara Benefit (manfaat) dengan Cost (biaya) pada Discount Rate tertentu. Rata-rata Net Present Value (NPV) usahatani duku per hektar pada Kelompok Tani Harapan Makmur di Dusun Cililitan Desa Karanganyar Kecamatan Cijeungjing adalah Rp. 35.758.175,22. Menurut Husnan dan Muhamad (2008) suatu proyek dikatakan layak diusahakan jika nilai $N P V$ nya lebih dari 0 . Jadi dapat disimpulkan usahatani duku pada Kelompok Tani Harapan Makmur di Dusun Cililitan Desa Karanganyar Kecamatan Cijeungjing layak diusahakan, karena nilai $N P V$ nya lebih dari 0 .

b) $\mathrm{Net} B / \mathrm{C}$

Nilai rata-rata $\mathrm{Net} B / C$ adalah 1,41 ini berarti setiap 1,00 modal yang ditanam pada usahatani duku akan memperoleh manfaat sebesar 1,41. Menurut Husnan dan Muhamad (2008) suatu proyek dikatakan layak diusahakan jika nilai $\mathrm{Net} B / C$ lebih dari 1. Jadi dapat disimpulkan usahatani duku pada Kelompok Tani Harapan Makmur di Dusun Cililitan Desa Karanganyar Kecamatan Cijeungjing layak diusahakan, karena nilai Net B/C nya lebih dari 1. 
c) IRR

Nilai rata-rata $I R R$ yang diperoleh sebesar 8,83 persen per tahun atau lebih besar dari tingkat bunga 7 persen. Menurut Husnan dan Muhamad (2008) suatu proyek dikatakan layak diusahakan jika nilai $I R R$ lebih besar dari tingkat bunga bank yang berlaku. Jadi dapat disimpulkan usahatani duku pada Kelompok Tani Harapan Makmur di Dusun Cililitan Desa Karanganganyar Kecamatan Cijeungjing layak diusahakan, karena nilai $I R R$ nya lebih dari bunga bank yang berlaku.

\section{d) Payback Period}

Payback Period diartikan sebagai jangka waktu pengembalian modal yang diinvestasikan dari suatu proyek, melalui keuntungan yang diperoleh dari suatu proyek. Perhitungan payback Period dilakukan dengan menghitung net benefit kumulatif karena benefit yang dihasilkan dalam kegiatan proyek usahatani tidak sama untuk setiap tahunnya.

$$
\text { Rata-rata jangka waktu }
$$

pengembalian modal yang diinvestasikan dalam kegiatan usahatani duku pada Kelompok Tani Harapan Makmur di Dusun Cililitan Desa Karanganyar Kecamatan Cijeungjing yaitu 20 tahun 6 bulan 20 hari.

\section{KESIMPULAN DAN SARAN}

\section{Kesimpulan}

Berdasarkan hasil penelitian dan pembahasan maka dapat diambil kesimpulan sebagai berikut :

1. Besarnya rata-rata biaya investasi usahatani duku per hektar pada Kelompok Tani Harapan Makmur di Dusun Cililitan Desa Karanganyar Kecamatan Cijeungjing sebesar Rp. 74.707.900,00. Rata-rata biaya operasional usahatani duku per hektar untuk tahun ke-1 sampai tahun ke-9 adalah Rp. 1.572.981,20 sedangkan rata-rata biaya operasional usahatani duku per hektar untuk tahun ke-10 sampai tahun ke-30 adalah $\mathrm{Rp}$. 7.066.812,00. Rata-rata penerimaan usahatani duku per hektar pada Kelompok Tani Harapan Makmur di Dusun Cililitan Desa Karanganyar Kecamatan Cijeungjing sebesar Rp. 1.023.753.600,00. Nilai rata-rata $N P V$ per hektar sebesar Rp. 35.758.175,22. Berarti responden memperoleh keuntungan pada tingkat bunga 7 persen sebesar Rp. 35.758.175,22. Nilai rata-rata Net $B / C$ sebesar 1,41 ini berarti setiap 1,00 modal yang ditanam pada usahatani duku akan memperoleh manfaaat sebesar 1,41. Nilai rata-rata 
IRR yang diperoleh sebesar 8,83 persen, hal tersebut menandakan bahwa tingkat bunga bank maksimum yang mampu dibayar oleh responden sebesar 8,83 persen per tahun atau lebih besar dari tingkat bunga 7 persen. Dilihat dari $N P V, N e t$ $B / C$ dan IRR maka usahatani duku pada Kelompok Tani Harapan Makmur di Dusun Cililitan Desa Karanganyar Kecamatan Cijeungjing layak untuk diusahakan, karena nilai $N P V$ nya lebih dari $0, N e t B / C$ lebih dari 1, dan IRR nya lebih besar dari tingkat bunga bank yang berlaku.

2. Rata-rata jangka waktu pengembalian modal yang diinvestasikan dalam kegiatan usahatani duku di Kelompok Tani Harapan Makmur Dusun Cililitan Desa Karanganyar yaitu 20 tahun 6 bulan 20 hari.

\section{Saran}

Berdasarkan kesimpulan tersebut, maka saran yang dapat diajukan yaitu usahatani duku yang dilakukan petani pada Kelompok Tani Harapan Makmur di Dusun Cililitan Desa Karanganyar Kecamatan Cijeungjing sebaiknya diteruskan dan ditingkatkan nilai investasinya dengan cara memperluas skala lahan.

\section{DAFTAR PUSTAKA}

Atmaja, U., dan Hartoyo, T. 2005. Optimasi Alokasi Lahan pada Sistem Pengelolaan Usaha Wanatani (Kasus Laboratorium Lapangan Watani Universitas Siliwangi). Kerjasama Universitas Siliwangi Tasikmalaya dan Balai Rehabilitasi Lahan dan Konservasi Tanah Cimanuk-Citanduy Ditjen Departemen Kehutanan RI. Tasikmalaya.

Azhari, DH., 2004. Dukungan Pengolahan dan Pemasaran Hasil terhadap Pengembagan Agribisnis Hortikultura. Makalah Disampaikan pada Pertemuan Sinkronisasi Pelaksanaan Pengembangan-Hortikultura 2004. Cisarua. Bogor.

Daniel, M. 2002. Metode Penelitian Sosial Ekonomi. Bumi Aksara. Jakarta.

Husnan, M. dan Muhamad, S. 2008. Studi Kelayakan Proyek. Unit Penerbit dan Percetakan. Yogyakarta.

Lutony, T. L. 2005. Duku Potensi dan Peluangnya. Kanisius. Yogyakarta.

Ritonga, A. 2003. Kependudukan dan Lingkungan Hidup. Jakarta: Fakultas Ekonomi UI.

Sugiyono. 2015. Metode Penelitian Pendidikan Pendekatan Kuantitatif, Kualitatif dan R\&D. Alfabeta. Bandung. 